\title{
Pemeriksaan Gula Darah Sewaktu (GDS) dan Tekanan Darah kepada Masyarakat
}

\author{
Maria Karolina Selano*, Veronica Ririn Marwaningsih, Niken Setyaningrum \\ ${ }^{1}$ Program Studi Keperawatan, Sekolah Tinggi Ilmu Kesehatan Elisabeth, Semarang, Indonesia
}

\author{
*Corresponding Author \\ Jl. Kawi No.11 Semarang, Telp/Fax 0248412729/0248506185 \\ E-mail: mariaselano100284@gmail.com
}

$\begin{array}{llll}\text { Received: } & \text { Revised: } & \text { Accepted: } & \text { Published: } \\ 25 \text { April 2020 } & \text { 8 May 2020 } & \text { 17 May 2020 } & 31 \text { May 2020 }\end{array}$

\begin{abstract}
Abstrak
Diabetes mellitus (DM) merupakan salah satu penyakit kronis yang paling banyak dialami oleh penduduk di dunia. Penyakit DM menempati urutan ke-4 penyebab kematian dinegara berkembang. Salah satu jenis penyakit DM yang paling banyak dialami oleh pendudukan di dunia adalah DM tipe 2 (85-95\%), yaitu penyakit DM yang disebabkan oleh terganggunya sekresi insulin dan resistensi insulin. Peningkatan jumlah kasus DM tipe 2 tersebut berdampak pada peningkatan komplikasi yang dialami pasien DM tipe 2. Komplikasi tersering yang dialami pasien DM tipe 2 adalah neoropati perifer (10-60\%) yang akan menyebabkan ulkus diabetic. Menurut American Diabetes Association (ADA) bahwa salah satu faktor risiko terjadinya diabetes mellitus adalah faktor risiko yang dapat diubah meliputi obesitas berdasarkan IMT $\geq 25 \mathrm{~kg} / \mathrm{m}^{2}$ atau lingkar perut $\geq 80 \mathrm{~cm}$ pada wanita dan $\geq 90 \mathrm{~cm}$ pada laki - laki, kurang aktivitas fisik, hipertensi, dislipidemi dan diet tidak sehat. Tujuan dari kegiatan pengabdian masyarakat ini adalah melakukan skrining awal penderita hipertensi dan penderita diabetes mellitus serta sebagai upaya peningkatan kesadaran masyarakat terkait deteksi dini penyakit hipertensi dan diabetes mellitus. Metode yang dilakukan dengan melakukan pemeriksaan gula darah sewaktu (GDS) dan tekanan darah kepada masyarakat. Hasil evaluasi telah teridentifikasi 18 orang $(13,84 \%)$ memiliki gula darah sewaktu $(G D S)>180 \mathrm{mg} / \mathrm{dl}$, sedangkan hasil pemeriksaan tekanan darah didapatkan 20 orang $(15,38 \%)$ memiliki tekanan darah > 120/80 MmHg.
\end{abstract}

Kata kunci : Diabetes Mellitus; Hipertensi; Pemeriksaan GDS; Pemeriksaan Tekanan Darah 


\begin{abstract}
Diabetes mellitus (DM) is one of the most common chronic diseases experienced by people in the world. DM disease ranks 4th place in the cause of death in developing countries. One of the most common types of DM disease experienced by occupation in the world is DM type 2 (85-95\%), which is DM disease caused by disruption of insulin secretion and insulin resistance. The increase in the number of cases of type 2 DM has an impact on the increased complications experienced by patients with type $2 \mathrm{DM}$. The most common complication experienced by type 2 DM patients is peripheral neoropathy (10-60\%) which will cause diabetic ulcers. According to the American Diabetes Association (ADA) that one of the risk factors for diabetes mellitus is a risk factor that can be changed include obesity based on $B M I \geq 25 \mathrm{~kg} / \mathrm{m} 2$ or abdominal circumference $\geq 80 \mathrm{~cm}$ in women and $\geq 90 \mathrm{~cm}$ in men, lack of physical activity, hypertension, dyslipidemia and unhealthy diet. The purpose of this community service activity is to conduct initial screening of hypertension sufferers and people with diabetes mellitus and as an effort to increase public awareness related to early detection of hypertension and diabetes mellitus. The method is carried out by checking blood sugar (GDS) and blood pressure to the public. The evaluation results have identified 18 people (13.84\%) have blood sugar when $(G D S)>180 \mathrm{mg} / \mathrm{dl}$, while the results of blood pressure examination found 20 people (15.38\%) have blood pressure $>120 / 80 \mathrm{MmHg}$.
\end{abstract}

Keywords: Diabetes Mellitus; Hypertension; GDS Test; Blood Pressure Check

\title{
PENDAHULUAN
}

Penyakit tidak menular (PTM), termasuk diabetes saat ini telah menjadi ancaman serius kesehatan global. Dikutip dari data WHO 2016, $70 \%$ dari total kematian di dunia dan lebih dari setengah beban penyakit. 90 - $95 \%$ dari kasus diabetes adalah diabetes tipe 2 yang sebagian besar dapat dicegah karena disebabkan oleh gaya hidup yang tidak sehat. Data dari International Diabetes Federation (IDF) Atlas 2017 melaporkan bahwa epidemi diabetes di Indonesia masih menunjukkan kecenderungan meningkat. Indonesia adalah negara peringkat keenam di dunia dengan jumlah penyandang diabetes usia $20-79$ tahun sekitar 10,3 juta orang. Sejalan dengan hal tersebut, Riset Kesehatan Dasar (Riskesdas) memperlihatkan peningkatan angka prevalensi yaitu 6,9\% di tahun 2013 menjadi 8,5\% ditahun 2018 sehingga estimasi jumlah penderita di Indonesia yang kemudian berisiko terkena penyakit lain seperti serangan jantung, stroke, kebutaan dan gagal ginjal bahkan dapat menyebabkan kelumpuhan dan kematian (Kemenkes, 2018 ).

American Diabetes Association menjelaskan diabetes mellitus sebagai jenis penyakit metabolik yang ditandai dengan hiperglisemia kronis yaitu tidak berfungsinya organ tubuh terutama mata, ginjal, saraf, jantung, dan pembuluh darah akibat kerusakan sekresi insulin, kerja insulin, ataupun keduanya, sehingga glukosa (gula darah) akan menumpuk dalam tubuh karena tidak dapat dipecah menjadi sumber energi. Rekomendasi aktifitas fisik dan tindakan pencegahan dapat bervariasi berdasarkan tipe diabetes. Pada diabetes tipe 1, hasil penghancuran autoimun sel pankreas beta menghasilkan defisiensi insulin. Meskipun dapat terjadi pada semua usia, tingkat kerusakan sel beta bervariasi, biasanya lebih cepat pada remaja dibandingkan pada orang dewasa. Diabetes tipe 2 merupakan hasil dari hilangnya sekresi insulin secara progresif biasanya juga dengan resistensi insulin. Keadaan ini dapat dicegah atau ditunda dengan aktifitas fisik dan perubahan gaya hidup (Colberg et al., 2010). 
Penderita diabetes melitus yang memiliki aktifitas fisik yang rendah memiliki resiko intoleransi glukosa 2,7 kali lebih tinggi dibandingkan mereka yang memiliki aktifitas fisik yang tinggi. Aktivitas fisik dan olahraga secara signifikan meningkatkan konduksi kecepatan saraf, fungsi sensorik perifer dan distribusi tekanan pada kaki. Selain itu, tingkat kejadian ulkus pada pasien diabetes mellitus yang melakukan aktifitas fisik lebih rendah dibandingkan pasien yang tidak melakukan aktifitas fisik. Data ini menunjukkan bukti bahwa aktivitas fisik dan olahraga adalah intervensi non-farmakologis yang efektif untuk meningkatkan kualitas hidup pasien dengan diabetes (Matos, Mendes, Silva, \& Sousa, 2018).

Tujuan dari kegiatan pengabdian masyarakat ini adalah melakukan skrining awal penderita hipertensi dan penderita diabetes mellitus serta sebagai upaya peningkatan kesadaran masyarakat terkait deteksi dini penyakit hipertensi dan diabetes melitus.

Penderita diabetes melitus yang tidak dikelola dengan baik akan meningkatkan resiko terjadinya komplikasi, karena pasien diabetes melitus rentan mengalami komplikasi yang diakibatkan karena terjadinya defisiensi insulin atau kerja insulin yang tidak adekuat. Komplikasi yang ditimbulkan bersifat akut maupun kronik. Komplikasi akut yang terjadi berkaitan dengan peningkatan kadar gula darah secara tiba - tiba, sedangkan komplikasi kronik sering terjadi akibat peningkatan gula darah dalam waktu yang lama (Yudianto, 2008). Ketika penderita diabetes mellitus mengalami komplikasi, maka akan berdampak pada menurunnya umur harapan hidup (UHP), penurunan kualitas hidup, serta meningkatkan angka kesakitan (Nwankwo et all, 2010).

Menurut Permana (2009), penyakit diabetes mellitus merupakan penyakit kronis yang akan diderita oleh penderita diabetes seumur hidup dan memiliki progresivitas yang akan terus berjalan sehingga lama - kelamaan akan menimbulkan komplikasi. Lamanya menderita diabetes mellitus berhubungan dengan komplikasi diabetes mellitus yang dialami oleh pasien. Komplikasi menyebabkan efikasi diri pasien rendah dan mengacu pada penurunan kualitas hidup (Husein, et all.,2010). Kontrol diabetes mellitus yang buruk dapat mengakibatkan hiperglikemia dalam jangka Panjang, yang menjadi pemicu beberapa komplikasi yang serius baik makrovaskular maupun mikrovaskular seperti penyakit jantung, penyakit vaskuler perifer, gagal ginjal, kerusakan saraf dan kebutaan. Banyaknya komplikasi yang mengiringi penyakit diabetes mellitus telah memberikan kontribusi terjadinya perubahan fisik, psikologis maupun sosial (Anani et al., 2012).

Mengingat tingginya prevalensi dan biaya perawatan untuk penderita diabetes mellitus maka perlu adanya upaya untuk pencegahan dan penanggulangan penyakit tersebut meliputi peningkatan edukasi, perilaku konsusmsi obat anti diabetes, latihan jasmani (aktifitas fisik), pengaturan makanan serta pengecekan berkala glukosa darah. Walaupun diabetes mellitus merupakan penyakit kronik yang tidak dapat menyebabkan kematian secara langsung, tetapi dapat berakibat fatal bila pengelolaannya tidak tepat. Pengelolaan diabetes mellitus memerlukan penanganan secara multidisiplin yang mencakup terapi non obat dan terapi obat. Penyakit diabetes mellitus memerlukan perawatan medis dan penyuluhan untuk self management yang berkesinambungan untuk mencegah komplikasi akut maupun kronis (Utomo, Julianti, \& Pramono, 2011). Salah satu upaya yang dapat dilakukan untuk meningkatkan pengetahuan masyarakat tentang penyakit diabetes mellitus adalah dengan kegiatan penyuluhan kesehatan (Ratnasari, 2019).

Diabetes mellitus merupakan penyakit yang ditandai dengan gangguan metabolisme glukosa akibat gangguan pengeluaran insulin, kerja insulin atau keduanya. Diabetes adalah salah satu penyebab utama kematian di dunia. Penyebab kematian pada pasien diabetes berasal dari komplikasi dari penyakit yang berhubungan dengan diabetes, penyakit jantung merupakan penyebab yang paling menonjol. Penatalaksanaan diabetes mellitus antara lain dengan pengaturan diet, latihan fisik dan pengobatan. Kepatuhan pasien diabetes melitus terhadap program pengobatan sangat penting untuk mencegah timbulnya komplikasi. Meskipun 
penatalaksanaan diabetes mellitus sangat kompleks, penderita yang mampu melakukan perawatan dirinya dengan optimal akan dapat mengendalikan glukosa darahnya, bertolak belakang dengan mereka yang tidak mampu mengendalikan kadar glukosa darahnya dengan baik, berbagai masalah akan muncul seperti luka ganggren, penurunan penglihatan dan neuropati (Fatehi et al, 2010).

\section{METODE}

\section{Waktu dan Tempat}

Kegiatan pengabdian kepada masyarakat ini dilakukan pada tanggal 30 April sampai dengan 03 Mei 2018 di halaman Sekolah Tinggi Ilmu Kesehatan Elisabeth Semarang. Alamat: Jl. Kawi Raya No.11, Wonotingal, Kec. Candisari, Kota Semarang, Jawa Tengah 50252.

\section{Bahan dan Alat}

Bahan dan alat yang digunakan terdiri dari Leaflet Pendidikan Kesehatan tentang Diabetes Melitus, Buku Panduan Pemeriksaan Gula Darah Sewaktu (GDS), glucometer dan strip glukosa, lancet, kapas alcohol, tensimeter, stetoskop, lembar catatan hasil pemeriksaan dan bolpoint.

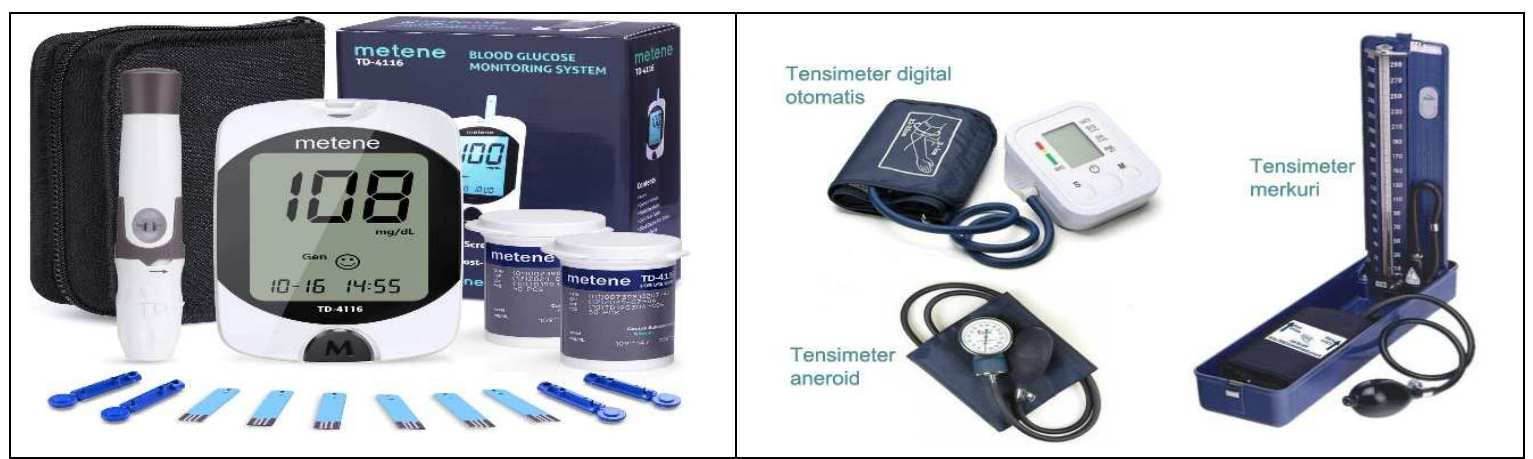

Gambar 1. Bahan dan alat dalam pelaksanaan pengabdian

\section{Cara Pemeriksaan}

Cara pemeriksaan yang dilakukan adalah dimulai dengan anamnesa atau wawancara untuk mengetahui identitas pasien, riwayat penyakit keturunan atau penyakit yang dialami kemudian dilakukan pemeriksaan gula darah sewaktu (GDS) dan pemeriksaan tekanan darah. Setelah dilakukan semua pemeriksaan, selanjutnya diberikan pendidikan kesehatan bagi anggota masyarakat tentang pola hidup sehat dan bersih serta menjaga gizi yang seimbang dengan menggunakan leaflet yang dibagikan kepada semua anggota masyarakat. Untuk anggota masyarakat yang memiliki hasil pemeriksaan gula darah sewaktu (GDS) dan tekanan darah diatas normal maka dianjurkan untuk segera memeriksakan diri ke layanan kesehatan terdekat untuk mencegah komplikasi yang akan terjadi.

\section{HASIL DAN PEMBAHASAN}

Hasil yang dicapai melalui kegiatan pengabdian kepada masyarakat ini dituangkan dalam bentuk hasil kegiatan pada setiap tahap pelaksanaan sebagai berikut :

\section{Perencanaan}

Kegiatan yang dilakukan dalam tahap perencanaan adalah :

a. Tim pengabdian kepada masyarakat mengadakan pertemuan dengan Ketua Lembaga Penelitian dan Pengabdian Masyarakat STIKes St. Elisabeth Semarang Ibu Natalia 
Ratna Yulianti, S.Kep.,Ns.,MAN pada tanggal 23 April 2018. Dalam pertemuan ini dukungan diberikan untuk melaksanakan kegiatan pengabdian kepada masyarakat ini.

b. Tim pengabdian masyarakat mengadakan pertemuan dengan Ketua STIKes St. Elisabeth Semarang Sr. Hedwig Parini, MSN pada tanggal 24 April 2018. Dalam pertemuan ini diberikan ijin untuk melaksanakan kegiatan pengabdian kepada masyarakat.

c. Penyusunan kegiatan Pemeriksaan Gula Darah Sewaktu (GDS) dan Tekanan Darah.

Berdasarkan hasil identifikasi permasalahan dan hasil analisis kebutuhan serta hasil analisis potensi STIKes St. Elisabeth Semarang, selanjutnya dilakukan kegiatan pemeriksaan gula darah sewaktu (GDS) dan tekanan darah.

2. Pelaksanaan Kegiatan

Tindakan dalam kegiatan ini adalam implementasi program. Kegiatan - kegiatan yang dilakukan dalam implementasi program adalah sebagai berikut :

a. Melakukan Pemeriksaan Gula Darah Sewaktu (GDS)

b. Melakukan Pemeriksaan Tekanan Darah

c. Melakukan Pendidikan Kesehatan (Penkes) tentang Pola Hidup Sehat dan Bersih serta menjaga Gizi yang Seimbang.

3. Evaluasi

Evauasi dilakukan dengan monitoring pelaksanaan kegiatan pemeriksaan gula darah sewaktu (GDS), pemeriksaan tekanan darah dan pemberian pendidikan kesehatan.

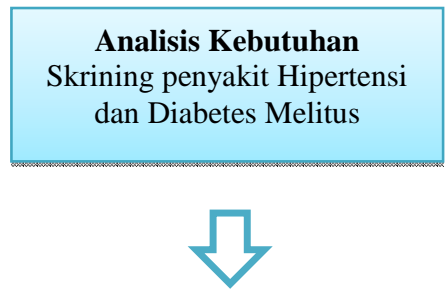

Proses Pelaksanaan Pemeriksaan Gula Darah Sewaktu

(GDS) dan Tekanan Darah

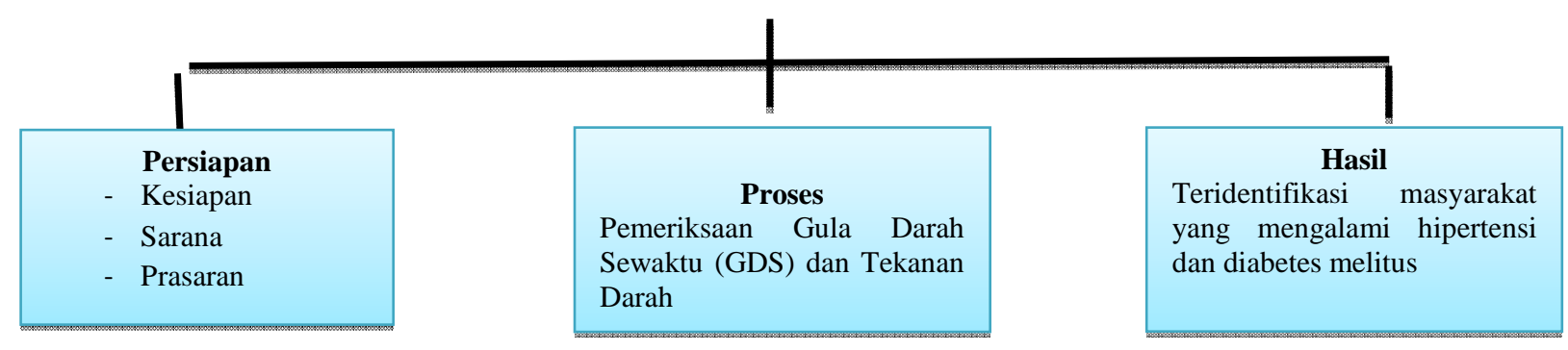

Gambar 2. Proses Pelaksanaan Kegiatan Pemeriksaan Gula Darah Sewaktu (GDS) dan Tekanan Darah

Kegiatan pemeriksaan gula darah sewaktu (GDS) dan tekanan darah ini dilakukan pada tanggal 30 April sampai dengan 03 Mei 2018 mulai pukul 08.00 WIB sampai dengan 14.00 WIB dihalaman Stikes St. Elisabeth Semarang.

Tim pengabdian masyarakat membuat surat undangan yang ditujukan kepada ketua RW di Kelurahan Wonotingal, Tegalsari, Candi dan Kaliwiru untuk mengundang anggota 
masyarakat mengikuti kegiatan pengabdian kepada masyarakat berupa pemeriksaan gula darah sewaktu (GDS), pemeriksaan tekanan darah dan pendidikan kesehatan.

Total masyarakat yang melakukan pemeriksaan gula darah sewaktu (GDS) dan tekanan darah berjumlah 130 anggota masyarakat yang terdiri dari 54 ( $41,53 \%)$ perempuan dan 76 $(58,46 \%)$ laki - laki.

Hasil pemeriksaan didapatkan 18 orang $(13,84 \%)$ memiliki gula darah sewaktu (GDS) > $180 \mathrm{mg} / \mathrm{dl}$, sedangkan hasil pemeriksaan tekanan darah didapatkan 20 orang $(15,38 \%)$ memiliki tekanan darah > 120/80 MmHg.

Tabel 1. Hasil Pemeriksaan Gula Darah Sewaktu (GDS) dan Tekanan Darah

\begin{tabular}{|c|c|c|c|c|}
\hline \multirow{2}{*}{$\begin{array}{l}\text { Tanggal } \\
\text { Periksa }\end{array}$} & \multicolumn{2}{|c|}{ Jumlah Periksa } & \multirow{2}{*}{$\begin{array}{c}\text { Jumlah Penderita } \\
\text { Diabetes }\end{array}$} & \multirow{2}{*}{$\begin{array}{c}\text { Jumlah Penderita } \\
\text { Hipertensi }\end{array}$} \\
\hline & Laki - laki & Perempuan & & \\
\hline 30 April 2018 & 13 & 11 & 4 & 2 \\
\hline 01 Mei 2018 & 16 & 20 & 5 & 6 \\
\hline 02 Mei 2018 & 14 & 36 & 6 & 8 \\
\hline 03 Mei 2018 & 11 & 9 & 3 & 4 \\
\hline Total & 54 & 76 & 18 & 20 \\
\hline
\end{tabular}

Sebagai pelaksana dalam kegiatan pengabdian kepada masyarakat ini adalah dosen keperawatan di STIKes St. Elisabeth Semarang yang memiliki pengetahun dan ketrampilan dalam pemeriksaan gula darah sewaktu (GDS) dan tekanan darah.

Keberlanjutan dalam kegiatan pengabdian kepada masyarakat ini dapat dijamin bermanfaat dalam deteksi dini penderita hipertensi dan diabetes melitus pada masyarakat. Pada saat melakukan pemeriksaan gula darah sewaktu (GDS) dan tekanan darah dimulai dari anamnesa atau wawancara untuk mengetahui identitas pasien, riwayat penyakit keturunan atau penyakit yang dialami kemudian dilakukan pemeriksaan gula darah sewaktu (GDS) dan pemeriksaan tekanan darah. Setelah dilakukan semua pemeriksaan, selanjutnya diberikan pendidikan kesehatan bagi anggota masyarakat tentang pola hidup sehat dan bersih serta menjaga gizi yang seimbang.

Tim dibagi dalam 3 bagian, bagian yang pertama melakukan anamnesa dan pemeriksaan gula darah sewaktu (GDS), tim yang kedua melakukan pemeriksaan tekanan darah dan tim yang ketiga melakukan pendidikan kesehatan kepada masyarakat dengan menggunakan leaflet yang dibagikan kepada anggota masyarakat. Pada saat memberikan pendidikan kesehatan, tim pengabdian masyarakat juga memotivasi anggota masyarakat yang teridentifikasi mempunyai hasil pemeriksaan gula darah dan tekanan darah diatas normal agar segera memeriksakan diri ke layanan kesehatan terdekat hal ini perlu dilakukan untuk mencegah komplikasi yang akan terjadi.

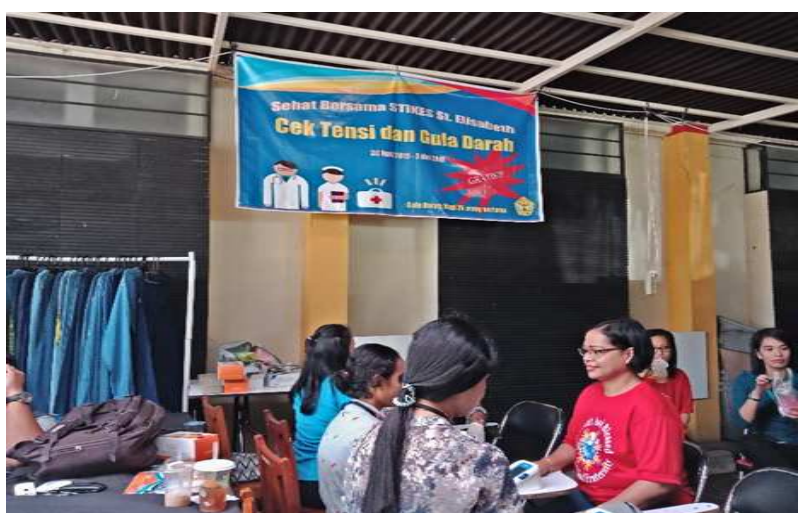

Gambar 3. Kegiatan Pemeriksaan Gula Darah Sewaktu (GDS) dan Tekanan Darah 


\section{KESIMPULAN}

Masyarakat perlu diberi pemahaman tentang pentingnya melakukan deteksi dini terkait penyakit diabetes mellitus dan hipertensi. Pemeriksaan gula darah sewaktu (GDS) dan tekanan darah adalah salah satu upaya untuk melakukan deteksi dini sehingga masyarakat dapat melakukan pencegahan. Penderita diabetes mellitus perlu diberikan pemahaman akan pentingnya patuh dalam berobat untuk menstabilkan kadar gula darah agar dapat menekan komplikasi yang akan terjadi, sehingga masyarakat patuh terhadap anjuran yang diberikan oleh tenaga kesehatan dalam kehidupan sehari - hari. Pada tahap kegiatan pengabdian masyarakat selanjutnya akan dilakukan pemberian senam kaki untuk menurunkan gula darah pada penderita diabetes mellitus.

\section{DAFTAR PUSTAKA}

Anani, S., Udiyono, A., Ginanjar, P., Fkm Undip, A., \& Bagian Epidemiologi dan, D. (2012). Hubungan Antara Perilaku Pengendalian Diabetes dan Kadar Glukosa Darah Pasien Rawat Jalan Diabetes Melitus (Studi Kasus di RSUD Arjawinangun Kabupaten Cirebon) (Vol. 1). Retrieved from http://ejournals1.undip.ac.id/index.php/jkm

Colberg, S. R., Sigal, R. J., Fernhall, B., Regensteiner, J. G., Blissmer, B. J., Rubin, R. R., ... American Diabetes Association. (2010). Exercise and type 2 diabetes: the American College of Sports Medicine and the American Diabetes Association: joint position statement executive summary. Diabetes Care, 33(12), 2692-2696. https://doi.org/10.2337/dc10-1548

Fatehi et al.,2010. Original Article. The Effect of Short Message Service on Knowledge of patient with Diabetes in Yazd Iran. Iranian Journal of Diabetes and Obesity. Volume 2. Number 1

Hussein, R. N.,Khther, S.A., - Hadithi, T.S. (2010). Impact of diabetes on physical and psychological aspects of quality of life of diabetic in Erbil city Iraq. Duhok Med J.4 (2), 45 - 59, November, 2, 2010. http://www.uod.ac/articles files/no 6.9.pdf.

Kementerian Kesehatan Republik Indonesia. (n.d.). Retrieved April 18, 2019, from http://www.depkes.go.id/article/view/18121200001/prevent-prevent-and-prevent-thevoice-of-the-world-fight-diabetes.html

Matos, M., Mendes, R., Silva, A. B., \& Sousa, N. (2018). Physical activity and exercise on diabetic foot related outcomes: A systematic review. Diabetes Research and Clinical Practice, 139, 81-90. https://doi.org/10.1016/j.diabres.2018.02.020

Nwankwo, C.H., et all. (2010). Factors Influencing Diabetes Management Outcome Among Patients Attending Government Health Facilities in South East, Nigeria. International Journal of Tropical Medicine, 5(2), 28-36

Ratnasari Y.N, (2019). Upaya pemberian penyuluhan kesehatan tentang diabetes mellitus dan senam kaki diabetic terhadap pengetahuan dan ketrampilan masyarakat desa Kedungringin, http://jurnal.unissula.ac.id/index.php/ijocs/article/view/4172/3057

Wonogiri.

Utomo, A. Y. S., Julianti, H. P., \& Pramono, D. (2011). Hubungan Antara 4 Pilar Pengelolaan Diabetes Melitus Dengan Keberhasilan Pengelolaan Diabetes Melitus Tipe 2. Retrieved from http://eprints.undip.ac.id/32797/ 
Indonesian Journal of Community Services

Volume 2, No. 1, May 2020

http://jurnal.unissula.ac.id/index.php/ijocs

DOI: http://dx.doi.org/10.30659/ijocs.2.1.38-45

Yudianto, Kurniawan, et all. (2008). Kualitas Hidup Penderita Diabetes Melitus di Rumah Sakit Umum Daerah Cianjur. Jurnal Keperawatan, 76. 